\title{
THRESHOLD CONCEPTS \& UNDERGRADUATE MATHEMATICS TEACHING
}

\begin{abstract}
Traditionally, many undergraduate mathematics courses have been defined in terms of mathematical content and the techniques in which students should become proficient or theorems they should be able to prove. This can result in a reliance on shallow, or rote learning by students, despite the fact that the main goal of a mathematics lecturer ${ }^{1}$ is usually to foster mathematical understanding in his/her students. In contrast, it is suggested that placing an emphasis on the threshold concepts involved in a course can enable teachers and students to focus on what is fundamental to the study and mastery of their subject.
\end{abstract}

Keywords: threshold concepts, course design

\section{INTRODUCTION TO THRESHOLD CONCEPTS}

The idea of a threshold concept emerged from a UK national research project (Enhancing Teaching-Learning Environments in Undergraduate courses, 2001-2005) designed to support departments involved in undergraduate teaching in thinking about new ways of encouraging high quality learning [5]. In pursuing this research in the field of economics, it became clear to Erik Meyer and Ray Land that certain concepts were held by economists to be essential to the mastery of their subject. These concepts were seen to have certain features in common and were called

\footnotetext{
${ }^{1}$ Here 'lecturer' is used to mean an academic who teaches, either full or part-time, at a university or similar institution and has full responsibility for the courses he/she teaches. A lecturer may also have research responsibilities.
} 
'threshold concepts' [16]. The notion of a threshold concept was introduced as a way of differentiating between learning outcomes that involved "seeing things in a new way" and those that did not. Threshold concepts have been described as portals, opening up a new and previously inaccessible view of a topic, a view without which students would be unable to fully progress intellectually. From that point of view, threshold concepts form a subset of what university lecturers would usually call 'core concepts.' A core concept is a conceptual building block: it must be understood but does not necessarily lead to a qualitatively different view of the subject manner.

Meyer and Land [16] originally identified five characteristics of a threshold concept: transformative, irreversible, integrative, bounded, and troublesome. What do they mean by these terms? Let us start with the idea that a threshold concept is transformative. Meyer and Land claim that once a threshold concept is understood, it has the potential to trigger a significant shift or transformation in the perception of a subject, or part thereof. The mastery of each threshold concept could be viewed as a step towards acquiring a professional's appreciation of the subject; this represents an ontological shift (or change in being) as well as a conceptual shift. The change in perception is unlikely to be forgotten and can be 'unlearned' only with considerable effort; therefore, this concept is considered irreversible. For this reason, it can be difficult for lecturers or experienced practitioners to appreciate the difficulties of their students as this requires them to look back over thresholds they have long since crossed. Threshold concepts often expose the inter-relatedness of a topic and allow connections which were previously hidden to be displayed. They can bring different aspects of a subject together and act as an anchor for the subject. From this perspective, they have been described as integrative. Often, but not necessarily, threshold concepts may lie on the border between conceptual spaces or may constitute the demarcation line between disciplinary areas. For this reason, they have been described as bounded. Finally, threshold concepts are troublesome, in part due to the characteristics described above, but also because they are often inherently conceptually difficult. The concept may appear to be counter- 
intuitive, paradoxical or incoherent, or may involve subtle distinctions being made between ideas.

In fact, Davies and Mangan [8] have argued that the transformative, integrative and irreversible characteristics of a threshold concept are necessarily interwoven:

A concept that integrates prior understanding is necessarily transformative, because it changes a learner's perception of their existing understanding. If a concept integrates a spectrum of prior understanding, it is more likely to be irreversible, because it holds together a learner's thinking about many different phenomena. To abandon such a threshold concept would be massively disruptive to an individual's whole way of thinking (p.712).

\section{THRESHOLD CONCEPTS IN MATHEMATICS}

Let us consider some candidates for the title threshold concept from the undergraduate mathematics curriculum.

\section{$2.1 \quad$ Limits}

When considering the attributes of a threshold concept, most readers will likely be reminded of the problems that students encounter with the $\epsilon-\delta$ definition of the limit of a function. Indeed, Meyer and Land included this as an example in their original work [16]. They remarked that

In pure mathematics the concept of a limit is a threshold concept; it is the gateway to mathematical analysis and constitutes a fundamental basis for understanding some of the foundations and application of other branches of mathematics such as differential and integral calculus (p.3).

Understanding the limit definition opens the door to the field of Analysis and sits on the boundary between Calculus and Analysis courses. (It could thus be thought of as bounded, using the terminology of [16].) 
The concept is certainly a troublesome one for most students, and this is not surprising since, historically, the evolution of the notion was slow. Even though Newton and Leibniz developed Calculus in the seventeenth century, and some of the ideas had previously been in use for a long time, it was not until the nineteenth century that Weierstrass finally formulated the $\epsilon-\delta$ definition [1, p.287].

There has been a considerable amount of research into the problems that students face with the notion of limit. These problems could be divided into two main categories: those that arise from pre-existing images of limits; and those that stem from the formulation of the definition itself [19]. Research has shown ([4], [18]) that the images that students have which relate to the word 'limit' can affect and inhibit their understanding of the concept when they meet it in an analysis course. Cornu [4] remarked that in the case of limits, both the phrase 'tends to' and the word 'limit' have interpretations in everyday life which are not always consistent with their mathematical meanings. For example, it carries the connotation of an impassable limit which is impossible to reach, a maximum or minimum, or a finishing point; each of these conceptions can cause problems for students even after they are introduced to the rigorous definition. On the other hand the structure of the definition itself causes problems; firstly it contains the quantifiers $\forall$ and $\exists$ which together prove confusing to students. Also, students often fail to see how the existence of a $\operatorname{limit}_{x \rightarrow a} f(x)=L$ can be inferred from a statement about inequalities such as $\forall \epsilon>0, \exists \delta$ such that $|f(x)-L|<\epsilon$ if $0<|x-a|<\delta[19]$. Students seem to want a formula or algorithm with which they can compute the limit ([18], [19]), and are uncomfortable with using the definition instead.

Anecdotally, students and mathematicians often report on the moment when the point of the $\epsilon-\delta$ definition became clear to them. The fact that they can remember a precise moment when this happened is significant and points to the transformative and irreversible nature of the new understanding.

Research has found ([23]) that further difficulties in understanding limits may arise from a mismatch between the (formal) concept defini- 
tion and students' concept image. Tall and Vinner ([23] p.151) defined the notion of a concept image as consisting of 'all the cognitive structure in the individual's mind that is associated with a given concept'. They found that for the topic of limits of functions, students' concept images may contain elements which do not agree with the definition or even with other parts of the concept image. Przenioslo [18] studied the conceptions of limit held by undergraduate students. She found that students had images of limits that were based on the formal definition, on the computation of limits using algorithms, on the dynamic nature of limits (ie thinking of values approaching a certain point), and on the function value at a point. She conjectured that the last three images were based on informal definitions used previously. In her study, the students whose images were close to the definition were usually more successful than the others at solving problems about limits, but also rarely reverted back to language such as 'getting closer and closer'. This also provides evidence that understanding the definition is a transformative and irreversible experience. This may be one reason why it is difficult to teach this topic, since once one has crossed the threshold with the limit definition, it is difficult to remember what it was like on the other side.

\section{$2.2 \quad$ Functions}

Even before students encounter the $\epsilon-\delta$ definition of the limit of a function, of course, they will have worked with the concept of function. This concept is fundamental in modern mathematics, and even though students are exposed to this idea in school, it has been found that many undergraduates have difficulties with it [3]. Pettersson [17] has suggested that the concept of function is a threshold concept.

The Mathematics Education community has conducted many studies into students' understandings of and difficulties with functions. Once again, as was the case with limits, we find that one of the main problems that students face is that of the definition. For example, Vinner and Dreyfus [25] found that students often think of functions as being a 
formula or an equation, and may be loath to accept functions that are not defined by a single algebraic expression. They may also expect all functions to be continuous. These problems with the definition of function bear similarities to the stages of the historic development of the concept [14], and so make a case for the concept to be described as inherently conceptually difficult (or troublesome).

Perhaps as a consequence of viewing functions as defined by an algebraic expression, students often think of them in terms of actions or an input-output model. For example, they may see $f(x)=5 x-2$ as a recipe for a series of calculations rather than as an object in its own right. To properly understand functions and to work with them in diverse areas of mathematics, students should be able to conceive of a function as an action, as a process, and as an object [2]. Sfard [22] discusses the complementary approaches of dealing with abstract notions such as functions: operationally as processes and structurally as objects. She introduced the term 'reification' to represent the transition of thought involved when a learner progresses to viewing processes as objects. She warns that reification is "an ontological shift, a sudden ability to see something familiar in a new light" (p.19) and a "rather complex phenomenon" (p.30), causing obstacles and frustration for learners: this reinforces a view of the concept as troublesome and illustrates how reification can be viewed as transformative. Gray and Tall [10] maintain that the ability to think flexibly in this manner (operationally and structurally) is at the root of successful mathematical thinking. They also suggest that the flexibililty in thought achieved by those who have experienced reification can explain why a mathematics expert may find it difficult to appreciate the difficulties of a novice, pointing to an irreversibility as described in [16]. Reification seems to be quite similar to what Thurston [24] called 'compression'. He spoke about learners of mathematics working step by step and struggling to understand a concept, but asserted that, once they have really understood the concept, their perspective can change to being able to see it as a whole. He believed such insight and mental compression can make it easier to recall and use the idea when it is needed in future. 
Finally, the idea of a function permeates many areas of mathematics, and as such a comprehensive understanding of the concept can expose previously hidden connections between different topics. Students usually first meet the formal definition of a function in the context of Analysis, but, once it is properly understood, they often come to realise how it can be related to linear systems and matrices they have encountered in Algebra, for instance. In this sense, it could be described as integrative.

\subsection{Cosets and Quotient Groups}

In contrast to the concepts of functions and limits, relatively little research has been carried out into the teaching and learning of Abstract Algebra. However, researchers have suggested that students' difficulties in Abstract Algebra courses seem to deepen when they meet the concepts of cosets and quotient groups $([13],[6])$. These concepts are crucial to the study of Group Theory, and so they could present an obstacle to further progression in Algebra. In a study of second-year undergraduate students at a British university, Ioannou [13] reported that students had problems visualising cosets. This led to students encountering problems understanding the remainder of their Group Theory course and also contributed to diminishing levels of engagement with the course.

Dubinsky and his colleagues [6] found that students were more comfortable with cosets when they could form them by carrying out calculationsthat is, by performing an action or following a process. However, they had difficulties when faced with the formation of cosets in unfamiliar settings. There was evidence that some students in that study saw cosets only in terms of an action or process to be carried out rather than as objects in their own right. This led to difficulties when thinking about cosets as elements of a quotient group. Students who could view cosets as objects were better able to answer difficult questions on the topic, and so, once this reification took place, it seemed to be transformative and probably irreversible. 


\section{THRESHOLD CONCEPTS AND IMPLICATIONS FOR UNDERGRADUATE MATHEMATICS TEACHING}

How can such research in mathematics education and the identification of threshold concepts inform the practice of mathematics teaching and learning? In An introduction to threshold concepts, Cousin [5] claims a

tendency among academic teachers is to stuff their curriculum with content, burdening themselves with the task of transmitting vast amounts of knowledge bulk and their students of absorbing and reproducing this bulk (p.4).

Criticism has been levelled at mathematics lecturers, in particular, for such a practice: Hillel [12] claims that, generally speaking, undergraduate mathematics courses have been defined in terms of mathematical content and the techniques students are expected to master or theorems they should be able to prove. Although the main goal of a mathematics lecturer may be to foster mathematical understanding in their students, such an understanding is seldom specifically nurtured by the mathematical tasks and assessments students are required to complete [20], leading many authors to decry an over-emphasis on procedures and the reproduction of definitions, statements of theorems etc., in undergraduate mathematics modules. Consequently, this can result in a reliance on shallow, superficial or rote learning by students and an inability to answer unseen problems or to apply or transfer their mathematical knowledge as appropriate [21]. For instance, Dreyfus [9] asserts that many students learn a large number of standardised procedures in their university mathematics courses, and, although they end up with a considerable amount of mathematical knowledge, they cannot use it in a flexible manner:

They have been taught the products of the activity of scores of mathematicians in their final form but they have not gained insight into the processes that have led mathematicians to create these products (p. 28). 
This is very much in contrast with the type of approach advocated by Land, Cousin, Meyer and Davies [15], who suggest that a focus on threshold concepts can enable teachers to make refined decisions about what is fundamental to the study and mastery of their subject. Because of the potentially powerful transformative effects of threshold concepts on the learning experience, they advocate treating threshold concepts as 'jewels in the curriculum' around which courses could be organised. In addition, since a poor understanding of these concepts can form a barrier to further advancement, they should be given particular attention when desgining the curriculum. If we, as mathematicians, can identify these concepts, we may be able to help give students both the tools and the time they need in order to develop a mastery of them. This may involve a recursive (as opposed to a linear) approach, revisiting threshold concepts at various stages and from various perspectives throughout a module or programme. Land et al. [15] advocate that a framework of engagement should be constructed by lecturers to facilitate the development of students' understanding of threshold concepts, actively engaging students with the conceptual material and allowing students to experience the 'ways of thinking and practicing' that are expected of practitioners in their discipline. In particular, they recommend that

tutors ask students to explain [a troublesome concept], to represent it in new ways, to apply it to new situations, to connect it to their lives. The emphasis is equally strong that they should not simply recall the concept in the form in which it was presented (p.57).

Teachers should be cautious when making assumptions about what students' uncertainties might be. As mentioned earlier, it can be difficult for experienced teachers to understand the obstacles met by students as they grapple with a difficult concept for the first time. Indeed, Thurston [24] (although he was not speaking about threshold concepts) also made this point and remarked that once you have mastered a concept it is very hard to "put oneself back in the mind of someone to whom they are mysterious" (p.848). This "puts a psychological barrier in the way of 
listening fully to students" ([24], p.848). Land et al. [15] advise lecturers to listen not just for what students know, but also for the terms that shape their knowledge and define their uncertainties and instabilities.

Land et al. [15] also discuss the "indispensable role of metacognition in the learning process" (p.59). They outline how lecturers should empathize with learners who are grappling with troublesome concepts, make sure that they are aware that others are experiencing similar difficulties, and encourage them to tolerate uncertainty in the short term. Students often abandon their studies due to conceptual difficulties, not realising that the confusion they are experiencing may be short-lived. It has also been suggested that students may be more likely to resort to mimicry or plagiarism if they feel they are alone in their confusion [5]. Furthermore, making students aware of the historical development of concepts may be useful not only in encouraging engagement with a concept, but also in allowing them to appreciate the difficulties experienced by those responsible for first articulating or formulating a concept, thereby encouraging perserverance.

We have seen that, for many threshold concepts, reification is an important part of the development of understanding and thus can serve as a marker of students' progress in learning mathematics. In mathematics teaching, however, reification often remains an implicit learning outcome, a form of tacit knowledge that is not explicitly articulated to learners. It may be that by focusing on threshold concepts in the curriculum, this process of reification can be addressed in a more explicit manner.

Some studies have been undertaken attempting to put these recommendations into practice. Harlow et al. [11] outline findings from a collaborative action-research project to document changes in lecturers' threshold-concept-informed teaching and their impact on student learning in analogue electronics. The lessons for teachers learned through this project are described as listening to students, tolerating learner confusion and revisiting threshold concepts, echoing the recommendations given by Land et al. [15]. Davies \& Mangan [7] have also endeavoured to put theory into practice in constructing a 'framework of engagement' 
for first-year undergraduate economics students. They blended insights from the theory of threshold concepts and variation theory to propose four pedagogic principles which were then translated into three types of teaching and learning activity - reflective exercises, problem-focussed exercises and threshold network exercises - and they report on their experiences of using these activities.

From a mathematics perspective, although Dubinsky et al. [6] do not frame their discussions of teaching group theory in general, and cosets in particular, in terms of threshold concepts, they make pedagogical recommendations in line with those described above and report some success from their efforts. For instance, they suggest "finding alternatives to linear sequencing" of material and state "it is the role of the teacher, not to eliminate [students'] frustration, but to help students learn to manage it" (p.300). In particular, using technology, they aim to help students experience reification by moving from viewing cosets in terms of actions to seeing them as objects.

\section{CONCLUDING REMARKS}

In this article we have described what is meant by a threshold concept, given examples of some mathematical concepts which have been identified as threshold concepts and discussed how they could be used in teaching and especially in curriculum design. In summary, lecturers should give special attention to threshold concepts, and use them as a central motif for courses; they should revisit the concepts frequently and view them from different perspectives if possible; they should become familiar with the literature on student misconceptions in order to help understand what difficulties students might face; they could make students aware that having difficulty understanding these concepts is common but not insurmountable. We have found the idea of a threshold concept and these recommendations both interesting and useful in developing our own teaching practice; we hope the wider mathematical community will do likewise. A comprehensive survey of research undertaken on threshold concepts can be found at 
http://www.ee.ucl.ac.uk/ mflanaga/thresholds.html

\section{REFERENCES}

\section{REFERENCES}

[1] BOYER, C.B. 1949. The History of the Calculus and its Conceptual Development. New York: Dover Publications.

[2] BREIDENBACH, D., E. DUBINSKY, J. HAWKS and D. NICHOLS 1992. Development of the process conception of function. Educational Studies in Mathematics. 23(3): 247-285.

[3] CARLSON, M. 1998. A cross-sectional investigation of the development of the function concept. In Schoenfeld, A.H., J. Kaput and E. Dubinsky (Eds.), Research in Collegiate Mathematics Education III. CBMS Issues in Mathematics Education (pp. 114-162). Providence, RI: American Mathematical Society.

[4] CORNU, B. 1992. Limits. In Tall, D. (Ed.), Advanced Mathematical Thinking (pp.153-166), Dordrecht: Kluwer Academic.

[5] COUSIN, G. 2006. An introduction to threshold concepts. Planet. 17: $4-5$.

[6] DUBINSKY, E., J. DAUTERMANN, U. LERON and R. ZAZKIS 1994. On learning fundamental concepts of group theory. Educational Studies in Mathematics. 27(3): 267-305.

[7] DAVIES, P. and J. MANGAN 2008. Embedding threshold concepts: From theory to pedagogical principles to learning activities. In Land, R., J.H.F. Meyer and J. Smith (Eds.), Threshold concepts in the Disciplines (pp.37-50). Rotterdam: Sense Press.

[8] DAVIES, P. and J. MANGAN 2007. Threshold concepts and the integration of understanding in economics. Studies in Higher Education. $32(6)$ : $711-726$. 
[9] DREYFUS, T. 1991. Advanced mathematical thinking processes. In Tall, D. (Ed.), Advanced Mathematical Thinking (pp.25-41). Dordrecht: Kluwer Academic Publishers.

[10] GRAY, E. and D. TALL 1994. Duality, ambiguity and flexibility: A 'proceptual' view of simple arithmetic. Journal for Research in Mathematics Education 25(2): 116-140.

[11] HARLOW, A., M. PETER, J. SCOTT and B. COWIE 2012. Students' perceptions of travel through liminal space: Lessons for teaching. http://www.nairtl.ie/documents/EPub_2012Proceedings.pdf. Accessed 5 May 2015.

[12] HILLEL, J. 2001. Trends in curriculum: A working group report. In Holton, D. (Ed.), The Teaching and Learning of Mathematics at University Level (pp.59-70). Dordrecht: Kluwer Academic Publishers.

[13] IOANNOU, M. 2010. Visualisation of cosets and its impact on student engagement with Group Theory. In Joubert, M. and P. Andrews (Eds.), Proceedings of the British Congress for Mathematics Education (pp.259-264). United Kingdom: BSRLM.

[14] KLEINER, I. 2012. Excursions in the History of Mathematics. Basel: Birkhauser.

[15] LAND, R., G. COUSIN, J.H.F. MEYER and P. DAVIES 2005. Threshold concepts and troublesome knowledge (3): implications for course design and evaluation. In Rust, C. (Ed.), Improving Student Learning Diversity and Inclusivity (pp.53-64). Oxford: OCSLD.

[16] MEYER, J.H.F. and R. LAND 2003. Threshold concepts and troublesome knowledge 1 - Linkages to ways of thinking and practising. In Rust, C. (Ed.), Improving Student Learning - Ten Years On (pp.412424). Oxford: OCSLD. 
[17] PETTERSSON, K. 2010. Threshold concepts: A framework for research in mathematics education. http://www . cerme7 . univ.rzeszow . pl/index . php?id=wg14. Accessed 5 May 2015.

[18] PRZENIOSLO, M. 2004. Images of the limit of function formed in the course of mathematical studies at the university. Educational Studies in Mathematics. 55: 103-132.

[19] ROH, K.H. 2010. An empirical study of students' understanding of a logical structure in the definition of limit via the $\epsilon$-strip activity. Educational Studies in Mathematics. 73: 263-279.

[20] SANGWIN, C. 2003. New opportunities for encouraging higher level mathematical learning by creative use of emerging computer assessment. International Journal of Mathematical Education in Science and Technology. 34(6): 813-829.

[21] SCHOENFELD, A.H. 1989. Explorations of students' mathematical beliefs and behavior. Journal for Research in Mathematics Education. 20: 338-355.

[22] SFARD, A. 1991. On the dual nature of mathematical conceptions: Reflections on processes and objects as different sides of the same coin, Educational Studies in Mathematics. 22(1): 1-36.

[23] TALL, D. and S. VINNER, 1981. Concept image and concept definition in mathematics with particular reference to limits and continuity, Educational Studies in Mathematics, 12: 151-169.

[24] THURSTON, W.P. 1994. Mathematical Education, Notices of the AMS. 37(7): 844-850.

[25] VINNER, S. and T. DREYFUS, 1989. Images and definitions for the concept of function, Journal for Research in Mathematics Education. 20(4): 356-366. 